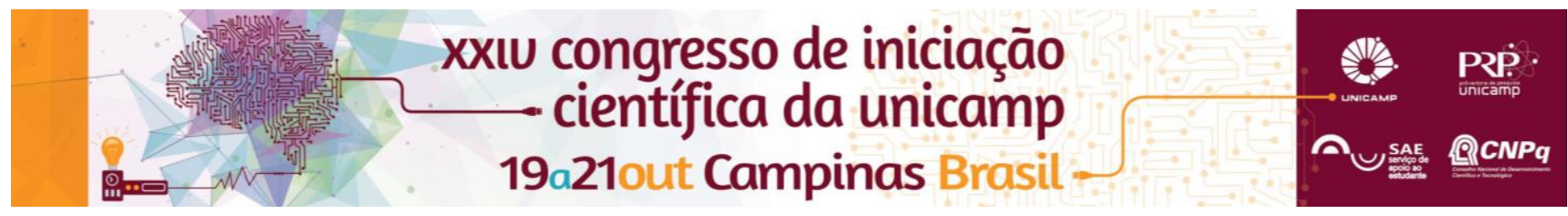

\title{
"VITAMIN D BASAL LEVELS AND AFTER REPLACEMENT, COGNITIVE DISORDERS, MUSCULAR STRENGTH AND FALLS IN ADULTS AND ELDERLY PEOPLE ATTENDED OR NOT AT UNIVERSITY HOSPITAL-PRELIMINARY RESULTS"
}

\section{Thais Junqueira P. Camargo*, Regina Maria I. Ruscalleda.}

\begin{abstract}
Determination of serum levels of vitamin D baseline and after replacement, and relate them to cognitive function, muscular strength and falls. The occurrence of inadequate levels of vitamin $D$ is frequent among adults and elderly people. Oral supplementation of vitamin D in this phase of the project was accomplished, however, participants did not achieve adequate serum levels.
\end{abstract}

\section{Key words: \\ Vitamin $D$, elderly people, cognitive disorders.}

\section{Introduction}

Reduced serum levels of $25 \mathrm{OH}$ vitamin D (25OHD3) are associated with increased risk of cognitive disorders ${ }^{1}$. Risk factors for falls: cognitive disorders, muscular weakness ${ }^{2}$, among others. Controlled studies suggest that vitamin D supplementation reduces the risk of falls ${ }^{3}$.

The objective of this study was the baseline determination of serum levels of vitamin D and after replacement and relate them to cognitive function, muscular strength and falls.

\section{Results and Discussion}

Two groups were established, G1, composed of 28 elderly patients attended at the University Hospital and G2 with 14 community individuals. All participated in a previous project and had inadequate serum levels of vitamin D (<30 ng / $\mathrm{mL}$ or $75 \mathrm{nmol} / \mathrm{L})$. Methods: Oral supplementation of vitamin D3, under medical supervision for six months, prescribed doses, depending on the vitamin D levels:> 20 to $30 \mathrm{ng} / \mathrm{ml}-1000 \mathrm{IU} /$ day; 10 to 20- 2000IU / day; <10 ng / ml- 3000Ul / day. Cognitive functions evaluation - Mini Mental State Examination (MMSE), Geriatric Depression Scale (GDS), basic activities (BADL), instrumental (IADL) of daily living and subclasses (I-independent A-aid, D-dependent); sociodemographic data- age, sex, number of diseases, scholarity; waist-hip ratio (WHR), occurrence of falls; consumption of milk and derivatives; grip strength test right and left hand (GS R, GS L), vitamin D serum levels (250HD total) by two methods: radioimmunoassay (RIA) and Chemiluminescence (Chemo).

Chart 1: Characterization of the groups $\mathrm{G} 1$ and $\mathrm{G} 2$

\begin{tabular}{|c|c|c|c|c|c|c|c|}
\hline Grove & ape jers) & sex & lintered & sua & wa & unse & 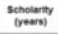 \\
\hline G1 & $79,8 \pm 10,5^{\circ}$ & 215 & $28+1,2^{2}$ & $1,0 \pm 1,2^{2}$ & $2,6 \pm 3,5^{\circ}$ & $21,3 \pm 5,5^{*}$ & $3,6 \pm 3,2^{*}$ \\
\hline$Q$ & $\begin{array}{l}64,5 \pm 6,9 \\
{ }^{2}<0,0001\end{array}$ & $\begin{array}{l}13 F \\
\text { IM }\end{array}$ & $\begin{array}{l}1,5 \pm 20 \\
t p=\end{array}$ & $\begin{array}{l}0,40,5 \\
p=0,0003\end{array}$ & $\begin{array}{l}0,3 \pm 1,1 \\
p_{p<0,0001}\end{array}$ & $\begin{array}{l}25,3 \pm 4,6 \\
p p=0.0018\end{array}$ & $\begin{array}{l}10,3 \pm 7,78 \\
\text { "pece0001 }\end{array}$ \\
\hline
\end{tabular}

Graphic 1: Vitamin D: RIA and Chemo basal vs after replacement

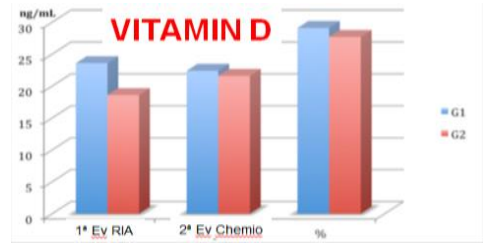

Chemiluminescence Method (ng / ml): G1-23.58 $\pm 17.83 \mathrm{X}$

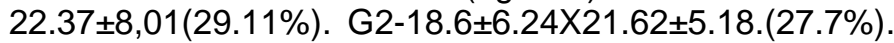
Concordance test between the two methods showed correlation coefficient 0.704 vs 0.936 (kit). This difference may be related to the $n, 73$ vs 587 , but allowed the comparison between the two determinations.

The vitamin $D$ levels were significantly higher in $G 1$ that showed falls $v s$ without falls $(26.17 \pm 9.66 \mathrm{ng} / \mathrm{ml} X 19.91$ $\pm 5.79 \mathrm{ng} / \mathrm{ml}$ )

It is likely that G1 participants which showed falls acted more consciously to the adherence to the replacement of vitamin D.

Statistically significant differences in the comparisons of the two ratings: G1- waist, WHR, BADL; G2-consumption of milk, GDS and between groups: Group G1> G2number of diseases, age, IADL, BADL; Group G1 <G2MMSE, scholarity. There were no significant statistical differences between the comparisons of the two evaluation for G1 and G2: MMSE, GS R, GS L. There is evidence that modifications of these variables would require more time standardization of the vitamin $D^{1,2,3}$.

Significant differences in both $\mathrm{G} 1$ assessments as to BADL and BADL A, waist measurements and WHR may be related to the aging process. There is evidence that increased consumption of milk and derivatives observed in $\mathrm{G} 2$ is related to the following guidelines awareness, attributed in part to the higher level of education of these participants.

\section{Conclusions}

The occurrence of inadequate levels of vitamin $D$ was found to be frequent among adults and elderly people. Oral supplementation of vitamin $D$ in this phase of the project was conducted, however, the participants have not achieved adequate levels.

\section{Acknowledgement}

Sponsor Institution: FAEPEX-FUNCAMP. Dra Sarah Monte Alegre/ Metabolic Unit.

1. Wilson VK, Houston DK, Kilpatrick L, Lovato J, Yaffe K, Cauley JA, et al Relationship Between 25-Hydroxyvitamin D and Cognitive Function in Older Adults: The Health, Aging and Body Composition Study. J Am Geriatr Soc. 2014;62:636-641

2-Tinetti M E. Preventing Falls in Elderly Persons. The New England Journal Of Medicine 2003; 348(1): 42-49.

3. Bischoff-Ferrari HA, Dietrich T, Orav EJ, Hu FB et al. Higher 25hydroxyvitamin $\mathrm{D}$ concentrations are associated with better lower-extremity function in both active and inactive persons aged $>$ or $=60 \mathrm{y}$. Am J Clin Nutr. 2004; 80(3):752-8. 